\title{
КОЛИЧЕСТВЕННОЕ ИЗМЕРЕНИЕ МАССОВОЙ ДОЛИ ДОБАВОК В ПОЛИЭТИЛЕНЕ МЕТОДОМ ВЫСОКОЭФФЕКТИВНОЙ ЖИДКОСТНОЙ ХРОМАТОГРАФИИ
}

Фазылзянов А.Р., Назипов М.Р., Марянина Е.В., Ананьева Г.С. ПАО «Казаньоргсинтез», Казань, Россия clo@kos.ru

DOI: 10.26902/ASFE-11_136

В ПАО «Казаньоргсинтез» для количественного измерения содержания стабилизаторов в полимерах применяются методы ИК-Фурье и УФ/Вид-спектроскопии с предварительной пробоподготовкой: в виде экстракции растворителем, либо подготовка образцов полимера прессованием. Данные методы исследования позволяют определять суммарное содержание стабилизаторов.

В данной работе представлен способ раздельного количественного измерения стабилизаторов при совместном присутствии в полиэтилене, методом высокоэффективной жидкостной хроматографии, с применением внутреннего стандарта. Применение внутреннего стандарта позволяет более точно определять содержание искомых компонентов, снизив погрешность методики. Пробоподготовка состоит из совместной экстракции стабилизаторов и внутреннего стандарта из полиэтилена растворителем в аппарате Сокслета. В качестве внутреннего стандарта для стабилизаторов вводится вещество, имеющее схожую химическую структуру с применяемыми в промышленности стабилизаторами и отсутствующее в пробе полимера. Далее полученный экстракт фильтруется и анализируется методом обращённофазовой хроматографии. Детектирование проводится в УФ-области спектра при длине волны 277 нм, поскольку при данной длине волны поглощение стабилизаторов является максимальным.

По результатам работы разработана методика количественного определения стабилизаторов методом высокоэффективной жидкостной хроматографии. Диапазон измерений составляет $(0,05 \div 0,5) \%$ масс.

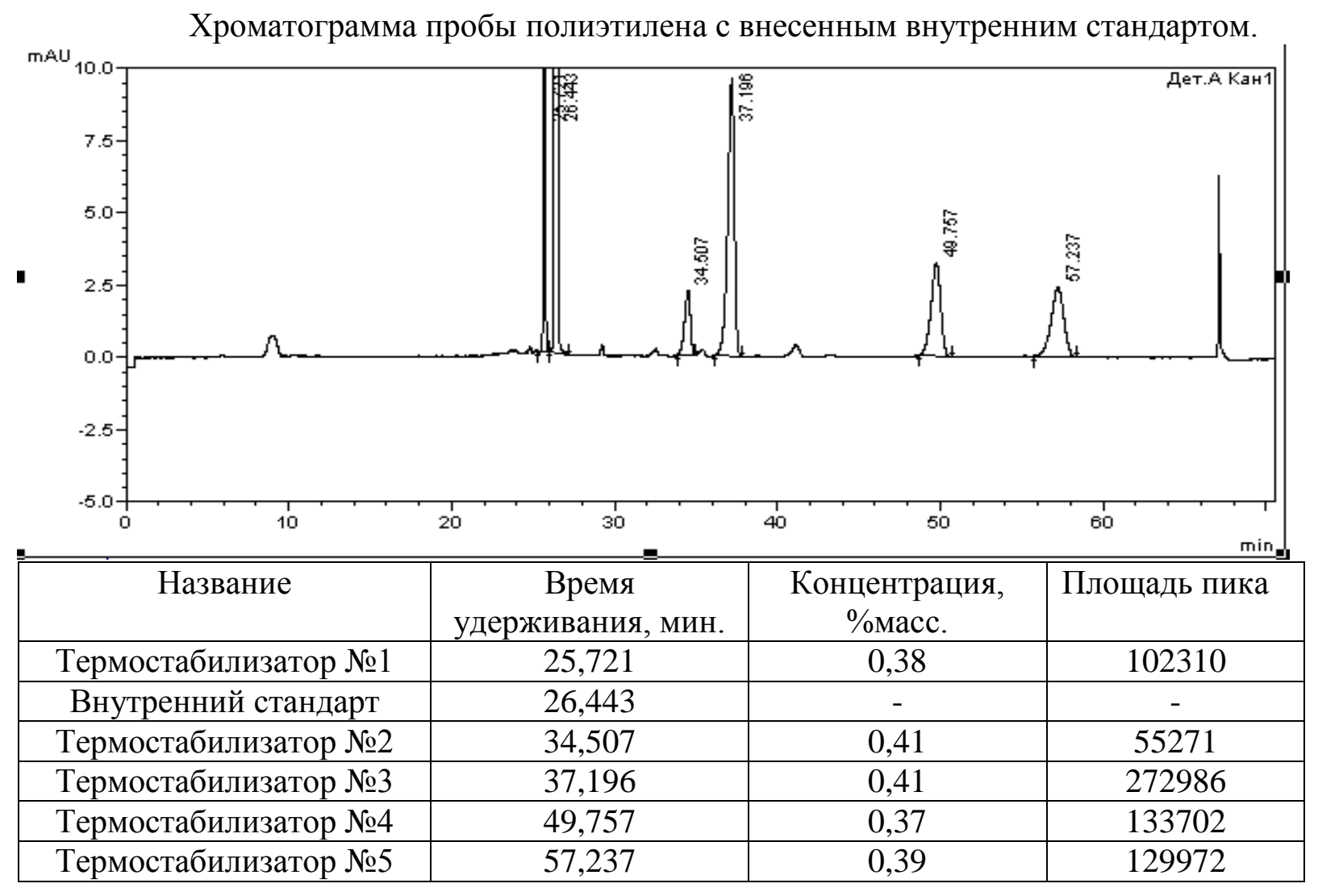

